\title{
inu \\ Capsaicin and Its Effect on Exercise Performance, Fatigue and Inflammation after Exercise
}

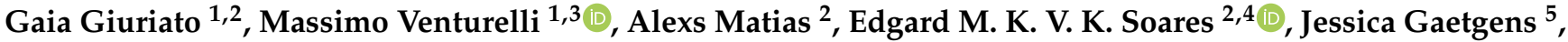 \\ Kimberley A. Frederick ${ }^{5}$ and Stephen J. Ives ${ }^{2, *}$ (])
}

check for updates

Citation: Giuriato, G.; Venturelli, M.; Matias, A.; Soares, E.M.K.V.K.; Gaetgens, J.; Frederick, K.A.; Ives, S.J. Capsaicin and Its Effect on Exercise Performance, Fatigue and Inflammation after Exercise. Nutrients 2022, 14, 232. https:// doi.org/10.3390/nu14020232

Academic Editor: David C. Nieman

Received: 6 December 2021

Accepted: 2 January 2022

Published: 6 January 2022

Publisher's Note: MDPI stays neutral with regard to jurisdictional claims in published maps and institutional affiliations.

Copyright: (C) 2022 by the authors. Licensee MDPI, Basel, Switzerland. This article is an open access article distributed under the terms and conditions of the Creative Commons Attribution (CC BY) license (https:// creativecommons.org/licenses/by/ $4.0 /)$.
1 Department of Neurosciences, Biomedicine and Movement Sciences, University of Verona, 37134 Verona, Italy; gaia-giuriato@univr.it (G.G.); Massimo.venturelli@univr.it (M.V.)

2 Health and Human Physiological Sciences Department, Skidmore College, Saratoga Springs, NY 12866, USA; amatias@skidmore.edu (A.M.); edgardsoares@gmail.com (E.M.K.V.K.S.)

3 Department of Internal Medicine, University of Utah, Salt Lake City, UT 84132, USA

4 Study Group on Exercise and Physical Activity Physiology and Epidemiology,

Exercise Physiology Laboratory, Faculty of Physical Education, University of Brasilia-UnB, Brasilia 70910-900, Brazil

5 Department of Chemistry, Skidmore College, Saratoga Springs, NY 12866, USA; jgaetgens@skidmore.edu (J.G.); kfreder1@skidmore.edu (K.A.F.)

* Correspondence: sives@skidmore.edu

\begin{abstract}
Capsaicin (CAP) activates the transient receptor potential vanilloid $1\left(\mathrm{TRPV}_{1}\right)$ channel on sensory neurons, improving ATP production, vascular function, fatigue resistance, and thus exercise performance. However, the underlying mechanisms of CAP-induced ergogenic effects and fatigueresistance, remain elusive. To evaluate the potential anti-fatigue effects of CAP, 10 young healthy males performed constant-load cycling exercise time to exhaustion (TTE) trials (85\% maximal work rate) after ingestion of placebo (PL; fiber) or CAP capsules in a blinded, counterbalanced, crossover design, while cardiorespiratory responses were monitored. Fatigue was assessed with the interpolated twitch technique, pre-post exercise, during isometric maximal voluntary contractions (MVC). No significant differences $(p>0.05)$ were detected in cardiorespiratory responses and self-reported fatigue (RPE scale) during the time trial or in TTE ( $375 \pm 26$ and $327 \pm 36 \mathrm{~s}$, respectively). CAP attenuated the reduction in potentiated twitch (PL: $-52 \pm 6$ vs. CAP: $-42 \pm 11 \%, p=0.037$ ), and tended to attenuate the decline in maximal relaxation rate (PL: $-47 \pm 33$ vs. CAP: $-29 \pm 68 \%, p=0.057$ ), but not maximal rate of force development, $\mathrm{MVC}$, or voluntary muscle activation. Thus, CAP might attenuate neuromuscular fatigue through alterations in afferent signaling or neuromuscular relaxation kinetics, perhaps mediated via the sarco-endoplasmic reticulum $\mathrm{Ca}^{2+}$ ATPase (SERCA) pumps, thereby increasing the rate of $\mathrm{Ca}^{2+}$ reuptake and relaxation.
\end{abstract}

Keywords: motoneuron; afferent; skeletal muscle; cardiac output; ventilation; metabolism; perfusion

\section{Introduction}

The primary pungent bioactive ingredient in hot peppers, capsaicin (CAP), has long been regarded for its therapeutic potential. Capsaicin (8-methyl-N-vanillyl-trans6-nonenamide) is classically described as an irritant and is a well-known endogenous activator of the transient receptor potential vanilloid type $1\left(\mathrm{TRPV}_{1}\right)$ on sensory neurons modulating signals for heat and/or pain. Exposure to CAP triggers a potent neuronal calcium influx, often followed by a reflex down-regulation of the TRPV 1 activity [1-3]. For this reason, CAP is a promising clinical tool to modulate TRPV 1 -related pathways, from pain perception [1-4], inflammation [5], and immunity [6], to most severe pathologies like schizophrenia [7], anxiety, depression [8], obesity [9] and chronic fatigue [10]. Ingestion of CAP increases thermogenesis by stimulating catecholamine secretion from the adrenal 
medulla, decreasing adipogenesis, and enhancing energy metabolism [11-15], improving mitochondrial biogenesis and adenosine triphosphate (ATP) synthesis, and is even suggested to improve markers of cardiovascular health [16-20].

In rodents, CAP elicits a spontaneous active behavior, increases grip strength and swimming time to exhaustion in a dose-dependent manner [21-24]. These enhancements in physical performance were correlated to increases in the hepatic glycogen content [21], likely as a result of glycogen sparing [24] and elevated fatty acid utilization due to CAPinduced adrenal catecholamine secretion [22]. Moreover, studies on mice showed that the $\mathrm{TRPV}_{1}$ activation by CAP administration upregulates PGC- $1 \alpha$, promotes mitochondrial biogenesis, increases the contribution of oxidative ATP production, and upregulates the expression of oxidative fibers in skeletal muscle $[25,26]$. In a murine model, CAP-induced muscular relaxation is mediated via a direct inhibitory action on the voltage-operated $\mathrm{Ca}^{2+}$ channels inside the cell [4]. In addition, a single high dose of CAP downregulates the expression of the mitochondrial uncoupling protein UCP3, and reduces the ATP cost of contraction, despite an unchanged, and at times increased, electrical twitch force generation $[25,27]$. Although CAP has been widely studied in cell and murine models, its acute in vivo physiological effects when combined with exercise have received relatively minimal attention, especially in humans.

Researchers have explored the effects of CAP ingestion and its influence on different exercise paradigms in healthy males [28-31]. Thus there have been some reports of performance improvements induced by the consumption of a single $12 \mathrm{mg}$ dose of purified CAP during a 1500-m running time trial [30], high-intensity intermittent exercise [28], and resistance training [29], but not during a $10 \mathrm{~km}$ running performance [31]. Additionally, CAP reduced the rating of perceived exertion (RPE) during the endurance and resistance tasks, with no between-group differences in lactate concentration, suggesting a possible mediating effect of CAP on fatigue or sensations of fatigue. On the contrary, Opheim and colleagues did not observe any effect of 7 days of ingestion of $28.5 \mathrm{mg}$ of CAP on performance or level of perceived fatigue during repeated sprint intervals $(15 \times 30 \mathrm{~m}$ sprints with intervals of $35 \mathrm{~s}$ ), but this dosing regimen induced significant gastrointestinal distress [32], highlighting the importance of dosage. Furthermore, these aforementioned studies on CAP focused solely on exercise performance, leaving the underlying mechanisms of CAP on the fatiguing process largely unexplored.

Exercise increases circulating concentrations of specific inflammatory cytokines, e.g., interleukin-6 (IL-6) and interleukin-1 $\beta$ (IL-1 $\beta$ ) $[33,34]$, which have been suggested as potential mediators of central nervous system fatigue in different diseases [35]. Highintensity exercise also increases salivary $\alpha$-amylase activity [36] and cortisol levels [37], which likely reflect the neuroendocrine response to exercise; cortisol has been shown to have anti-inflammatory properties, so the inflammatory and anti-inflammatory responses should be considered together. Furthermore, CAP has known analgesic and anti-inflammatory properties, along with the capacity to reduce the expression of several proinflammatory cytokines and chemokines [38,39]. To our knowledge, no studies, to date, have investigated the potential mechanisms of CAP-associated performance improvements, specifically whether CAP may alter the inflammatory or endocrine responses to exercise and thereby influence the fatigue response in humans.

Accordingly, given the paucity of data, we sought to explore the potential impact of acute oral CAP consumption on exercise performance, fatigue, and the inflammatoryendocrine response using a blinded, placebo-controlled, counterbalanced crossover design. The primary goal of our study was to better understand the intrinsic physiological effects of capsaicin administration in young, healthy individuals and to fill a gap in the literature concerning the ergogenic and fatigue-resistance of capsaicin in humans. To accomplish this, we employed the twitch interpolation technique to reveal the extent of peripheral fatigue and interpret the central nervous system contribution (voluntary activation) to the maximal voluntary contraction. We hypothesized that CAP supplementation would improve cycling performance and/or attenuate the observed neuromuscular fatigue after a cycling exercise 
time to exhaustion trial using the interpolated twitch technique, which might be due to an attenuated endocrine and inflammatory response to exercise.

\section{Materials and Methods}

\subsection{Subjects and General Procedures}

Thirteen young and physically active males were recruited for this study from Skidmore College and the surrounding community. To be included, participants must have been healthy without any history of cardiovascular, neuromuscular, pulmonary, or metabolic diseases. Additionally, participants could not be current or recent (less than 6 months) smokers, have any known allergies and/or excessive sensitivity to spicy foods (i.e., hot peppers, jalapenos, paprika, etc.) or fiber (psyllium husk). Participants' health history and eligibility were screened using health questionnaires to assess for eligibility (AHA/ACSM Pre-Participation Screening Questionnaire and Physical Activity Readiness Questionnaire [PAR-Q]). Participants were asked to refrain from consuming any vitamins or ergogenic supplements (i.e., L-Arginine, Citrulline-Malate, Pre-Workout) at least 2 days prior to each experimental visit, and to abstain from alcohol and caffeine, $24 \mathrm{~h}$ prior to testing. They were asked to report to the lab $2 \mathrm{~h}$ prior to the tests. All participants provided written informed consent prior to participation in the study. The study protocol was conducted in accordance with the most recent revisions of the Declaration of Helsinki and was approved by the Institutional Review Board (IRB\#1807-733) and Institutional Biosafety Committees of Skidmore College.

\subsection{Experimental Design}

The subjects reported to the laboratory on three different days, with a minimum of $72 \mathrm{~h}$ between sessions (See Figure 1). Anthropometric and body composition data were collected on the first session using air displacement plethysmography (Bod Pod, Cosmed, Concord, CA, USA) [40]. Participants were then asked to perform a maximal incremental test on a magnetically braked cycle ergometer (828E, Monark, Cosmed, Vansbro, Sweden) starting at $50 \mathrm{~W}$ with increments of $25 \mathrm{~W} / \mathrm{min}$, at a self-selected cadence that was maintained for the duration of the incremental test as well as subsequent experimental trials. The test continued until participants were unable to continue the prescribed workload. At the end of the session, participants were familiarized with the isometric maximal voluntary contractions and the electrically evoked muscle contractions. In a single-blinded, counterbalanced, crossover design, on days 2 and 3, participants were asked to ingest either $2 \times 390 \mathrm{mg}$ of CAP capsules (Capsicool, Natures Way, Medley FL, USA) or $2 \times 500$ mg placebo pills (PL; Fiber, Psyllium Husk, Kirkland Signature, Seattle, WA, USA). The capsules were of similar appearance (e.g., color, size, etc.), taste (both were encased with cellulose/hypromellose capsules), and were coded inconspicuously to ensure blinding. The dosing was in accordance with manufacturer-suggested guidelines and was well-tolerated in pilot testing. The time to peak in serum concentration of CAP after oral ingestion is $\sim 1 \mathrm{~h}$ [41]; for this reason, fatigue assessment at rest was assessed 50 min after pill ingestion to ensure adequate bioavailability. This was followed by a constant-load cycling exercise (85\% of peak power output) to exhaustion (TTE) and another fatigue assessment immediate post-exercise ( $\leq 60 \mathrm{~s}$ ). The neuromuscular assessment consisted of 6 maximal voluntary contractions (MVC) and superimposed twitch, pre and post the time to exhaustion trial. The bike test was terminated when the subjects could not maintain the self-selected pace for more than $10 \mathrm{~s}$. Saliva samples were collected three times during experimental trials: before starting the first neuromuscular assessment, after the last neuromuscular assessment, and after $5 \mathrm{~min}$ of recovery. 


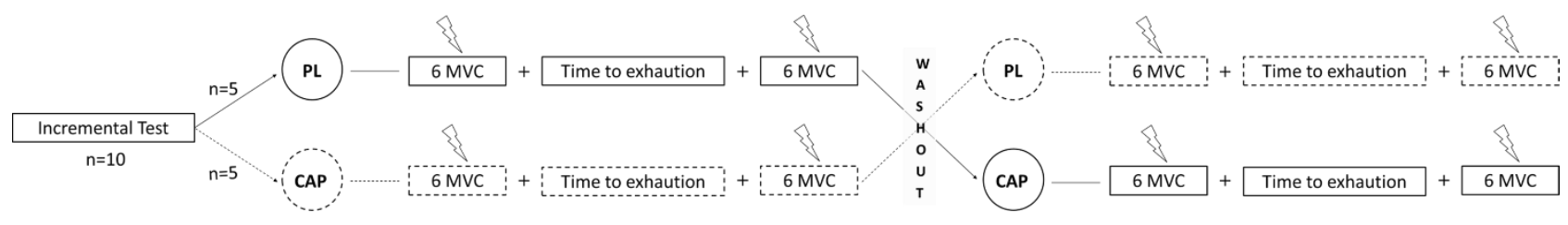

Figure 1. Experimental design of the study. After familiarization, participants reported to the lab on the first day for an incremental test. One week later, they were allocated in one of the two conditions, placebo (PL) or capsaicin (CAP). The neuromuscular assessment then started with 6 maximal voluntary contractions (MVC) using the interpolated twitch technique, which was repeated immediately following the time to exhaustion trial $\left(85 \% \mathrm{~W}_{\text {peak }}\right.$ of the incremental test). After one week of washout, the participants proceeded with the same assessments with the other condition.

\subsection{Cardiorespiratory Exercise Responses}

Ventilation $\left(\mathrm{V}_{\mathrm{E}}\right)$ and pulmonary gas exchange $\left(\mathrm{VO}_{2}, \mathrm{VCO}_{2}\right)$ were measured breath-bybreath at rest and during the two trials through a mouthpiece and one-way non-rebreathe valve (Hans Rudolph 2700, Shawnee, KS, USA), nose clip, and the expiratory port coupled to a metabolic cart (TrueOne 2400, Parvomedics, Sandy, UT, USA) [42]. At the same time, central hemodynamic markers (HR: heart rate; SV: stroke volume; CO: cardiac output) were collected using a non-invasive thoracic impedance cardiograph (PhysioFlow ${ }^{\circledR}$, Paris, France). The validity and reliability of this method have previously been established [43].

\subsection{Assessment of Neuromuscular Function and Fatigue}

The following methods were conducted in a manner similar to previous studies $[44,45]$. Accordingly, after proper skin preparation, two full-surface solid adhesive hydrogelstimulating electrodes (size: $50 \times 90 \mathrm{~mm}$, Myotrode Plus, Globus G0465) were applied on the quadriceps: the anode was placed on the proximal part of the thigh, while the cathode was placed on the distal part of the leg extensors, $3 \mathrm{~cm}$ above the patella. The stimulation intensity was determined before the measurements by 25-mA increments until the size of the evoked twitch and compound muscle action potential (M-wave) demonstrated no further increase. The stimulated twitch force was measured by an adequately calibrated force transducer (MLP-300; Transducer Techniques, Temecula, CA, USA) statically connected to a custom-made chair through a non-compliant strap placed around the ankle of the self-reported dominant limb (right leg in all cases). The subjects were seated with a $90^{\circ}$ knee flexion during the fatigue assessments. The superimposed twitch (SIT) and the resting twitch force $\left(Q_{t w, p o t}\right)$ were measured during a 5-s MVC of the knee extensors and after 2-s of relaxed muscle. This procedure was repeated six times before and after the time to exhaustion cycling exercise. The data of the three best MVCs were analyzed and averaged. Voluntary muscle activation (VMA\%) was calculated as VMA \% $=\left[1-\left(\mathrm{SIT} / \mathrm{Q}_{\mathrm{tw}, \mathrm{pot}}\right) \times 100\right]$. Peak force, maximal rate of force development (MRFD), and maximal relaxation rate (MRR) were analyzed for all $Q_{t w, p o t}$. Peak force was calculated as the highest value reached for every $Q_{t w, p o t}, M R F D$, and peak MRR of the resting twitch were calculated as the maximal steepness of the slope over a 10-ms interval. Data were collected using a Biopac system (MP150) and recorded using the AcqKnowledge A-D acquisition system (v. 4.4, Biopac, Goleta, CA, USA) on a separate computer. All data during the time to exhaustion were analyzed every $30 \mathrm{~s}$. To understand the potential impact of CAP on perceptions of fatigue, we assessed the whole-body and leg rate of perceived exertion $\left(\mathrm{RPE}_{\mathrm{tot}}\right.$ and $R P E_{\text {leg }}$, respectively) each minute during the trials.

\subsection{Microvascular Oxygenation}

Microvascular oxygenation was monitored with a multi-distance frequency-resolved near-infrared spectroscopy oximeter (NIRS; Oxiplex TS; ISS, Champaign, IL, USA). The NIRS technique provides non-invasive and continuous measurements of oxygenated $\left(\mathrm{HbO}_{2}\right)$, deoxygenated $(\mathrm{HHb})$, and total (Hbtot) hemoglobin levels, at a frequency of $2 \mathrm{~Hz}$. The probe was calibrated each time prior to use and then positioned on the vastus 
lateralis of the non-dominant (left) leg, and secured with adhesive tape and a bandage to avoid light contamination, as in prior studies [46-48]. Due to identical spectral qualities, hemoglobin and myoglobin cannot be uniquely identified using NIRS, and thus represents a conglomerate signal.

\subsection{Salivary Analysis}

Samples of 1-mL whole saliva were collected as indicated above, via passive drool technique, and immediately stored at $-80^{\circ} \mathrm{C}$ until assay. Analysis of cortisol, IL-1 $\beta$, IL-6, and $\alpha$-amylase was conducted using commercially available ELISA and enzymatic kits (Salimetrics, Carlsbad, CA, USA). The assays were run with samples/standards in duplicate, in accordance with manufacturer guidelines, and read with a colorimetric spectrophotometer (iMark, Biorad, Hercules, CA, USA). The linearity for these assays was $R^{2}>0.99$, while the coefficient of variation $(\mathrm{CV})$ was $<5 \%$ on standards for all assays.

\subsection{Biochemical Analysis of Capsules}

Capsaicin supplements $(n=3)$ and control fiber supplements $(n=3)$ were analyzed by extraction with ethanol to quantify the amount of the analytes capsaicin and dihydro-

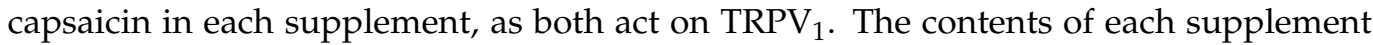
were combined in $1.5 \mathrm{~mL}$ of ethanol and left to extract for eight hours in an oven at $80{ }^{\circ} \mathrm{C}$ with periodic shaking. The samples were filtered and the extract was analyzed by HPLC (Thermo Vanquish, Waltham, MA, USA) with mass spectrometric detection (Thermo ISQEC, Waltham, MA, USA) in order to quantify the capsaicin and dihydrocapsaicin content. External standards were used for calibration with a typical intra-assay $\mathrm{CV}$ of $3 \%$ and linearity of $R^{2}>0.995$.

\subsection{Statistical Analysis}

In a one-tailed, paired-sample design, an effect size of 0.8 , and an alpha of 0.05 , a sample size of 12 participants was estimated to ensure a statistical power of 0.80 (G*Power software, Kiel, Germany). Statistical comparisons were performed with commercially available software (Prism v. 8.0, GraphPad Software, San Diego, CA, USA). Data during the TTE (cardiovascular, ventilatory, inflammatory, and RPE variables) were analyzed using a two-way repeated-measures analysis of variance (ANOVA) to evaluate the differences between trials. Tests of normality and assumptions were conducted, if a significant violation was found, an appropriate adjustment to the degrees of freedom was made. For the TTE, the last time point was the subjective time to task failure. Paired samples t-tests were used to assess the differences between conditions in the pre-to-post TTE changes in the neuromuscular assessments. Statistical significance was declared when $p<0.05$. Data are presented as Means $\pm \mathrm{SD}$, unless otherwise stated.

\section{Results}

\subsection{Participant Characteristics}

Ten young, healthy, and physically active males met all inclusion criteria and completed all trials (Table 1 ). The pre-exercise cardiorespiratory parameters were not different between trials (all $p>0.05$, data not shown).

Table 1. Participant Characteristics.

\begin{tabular}{cc}
\hline Variable & Mean \pm SD \\
\hline Age (years) & $22.3 \pm 3.6$ \\
Height $(\mathrm{cm})$ & $182 \pm 10$ \\
Weight $(\mathrm{kg})$ & $81.3 \pm 11.5$ \\
Fat Mass $(\%)$ & $11.7 \pm 1.5$ \\
Peak Aerobic Power (Watts) & $340 \pm 21$ \\
Peak Oxygen Consumption (VO 2 peak, $\mathrm{mL} / \mathrm{kg} / \mathrm{min})$ & $49.5 \pm 8.1$ \\
\hline
\end{tabular}




\subsection{Supplement Analysis}

Sample tracing of absorbance spectra for Capsaicin and dihydrocapsaicin used for subsequent quantification are presented in Figure 2. The average capsaicin content in each supplement was $0.957 \mathrm{mg} /$ tablet with a range of $0.951-0.969 \mathrm{mg} /$ capsule, thus the total dose was $1.914 \mathrm{mg}$. For dihydrocapsaicin, the average was $0.329 \mathrm{mg} /$ capsule with a range of $0.326-0.332 \mathrm{mg} /$ capsule, thus the total dose was $0.658 \mathrm{mg}$. The control fiber supplements contained no detectable levels of capsaicin or dihydrocapsaicin.

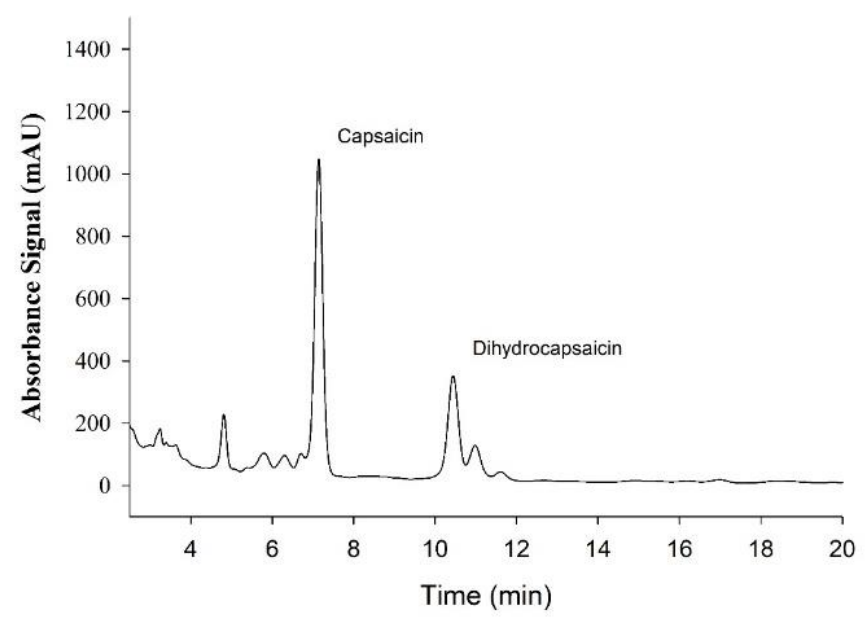

Figure 2. Sample Absorbance signal from High-Performance Liquid Chromatography (HPLC) analysis of Capsaicin supplement used for the quantification of the Capsaicinoids, Capsaicin, and Dihydrocapsaicin.

\subsection{Exercise Performance, Neuromuscular Function and Fatigue}

Both placebo and capsaicin conditions showed similar exhaustion (TTE) time of $375 \pm 26$ and $327 \pm 36 \mathrm{~s}$, respectively $(p>0.05$, Figure $3 \mathrm{~A})$. Regarding the force before exercise, the MVCs were not different between the two conditions (640 \pm 127 vs. $643 \pm 161 \mathrm{~N}$, $p>0.05)$, as well as after the TTE ( $479 \pm 125$ vs. $499 \pm 133 \mathrm{~N}, p>0.05)$. Accordingly, the baseline resting twitches ( $\mathrm{Q}_{\mathrm{tw}, \text { pot }}$ ) showed similar values ( $201 \pm 64$ vs. $\left.205 \pm 59 \mathrm{~N}, p>0.05\right)$, but trended towards a greater $\mathrm{Q}_{\mathrm{tw} \text {,pot }}$ immediately following exercise in the CAP condition as compared to the PL condition ( $100 \pm 28$ vs. $116 \pm 37 \mathrm{~N}, p=0.07$, Figure $4 \mathrm{~F})$. This is also seen in the percentage change in post-exercise decline in $\mathrm{Q}_{\mathrm{tw}, \text { pot }}$ in the two conditions, which reached statistical significance ( $-52 \pm 6$ vs. $-42 \pm 11 \%, p=0.037$, Figure $4 \mathrm{E})$. When the potentiated twitch ( $\mathrm{Q}_{\mathrm{tw}, \text { pot }} \%$ ) was plotted as a function of TTE, significant positive correlation with both PL $(r=0.7, p=0.04)$ and CAP $(r=0.7, p=0.04)$ was observed (Figure 3B). VMA\% was not affected by either exercise or the supplement $(p>0.05)$. Looking at the intrinsic muscle contractile functions, MRR and MRFD showed significant reductions in pre-to-post TTE $(p<0.000)$. In addition, CAP mitigated the exercise-induced decline in MRR $(p=0.01$; Figure 4 C). Specifically, in the PL condition, MRR was reduced by $57 \pm 22 \%$, while only attenuated by $41 \pm 19 \%$ in CAP. In contrast, MRFD decreased similarly in both conditions, namely, by $55 \pm 16 \%$ and $49 \pm 21 \%$ in PL and CAP, respectively (Figure 4D). 


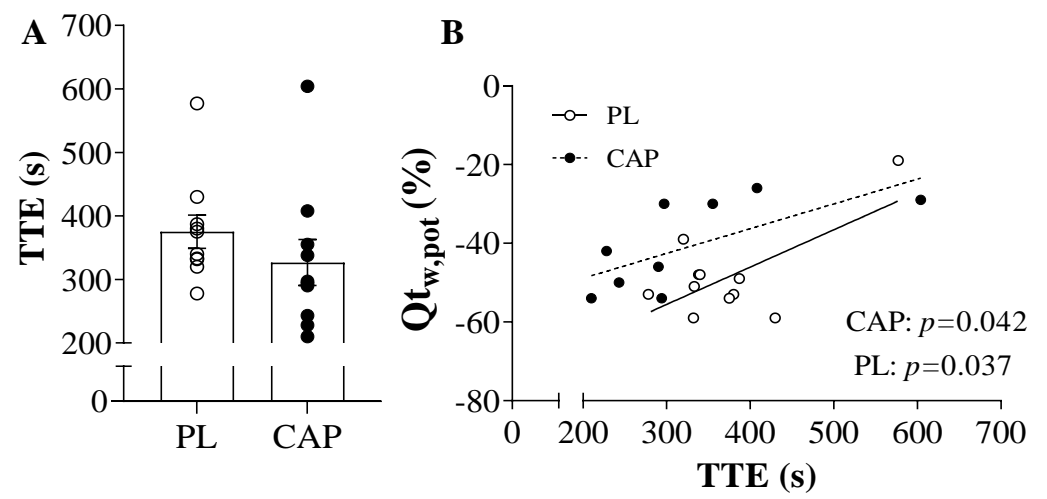

Figure 3. Time to exhaustion (TTE) and its correlation with the resting potentiated twitch (QT w,pot $)$ after exercise $(n=10)$. (A) Time to exhaustion in individual valued after CAP or PL ingestion; (B) Time to exhaustion correlated with the $\mathrm{QT}_{\mathrm{W} \text {, pot }}$ showed a significant positive correlation in both PL $(r=0.7$, $p=0.04)$ and CAP $(r=0.7, p=0.04)$. Values are presented as individual data and Mean $\pm \operatorname{SEM}$.
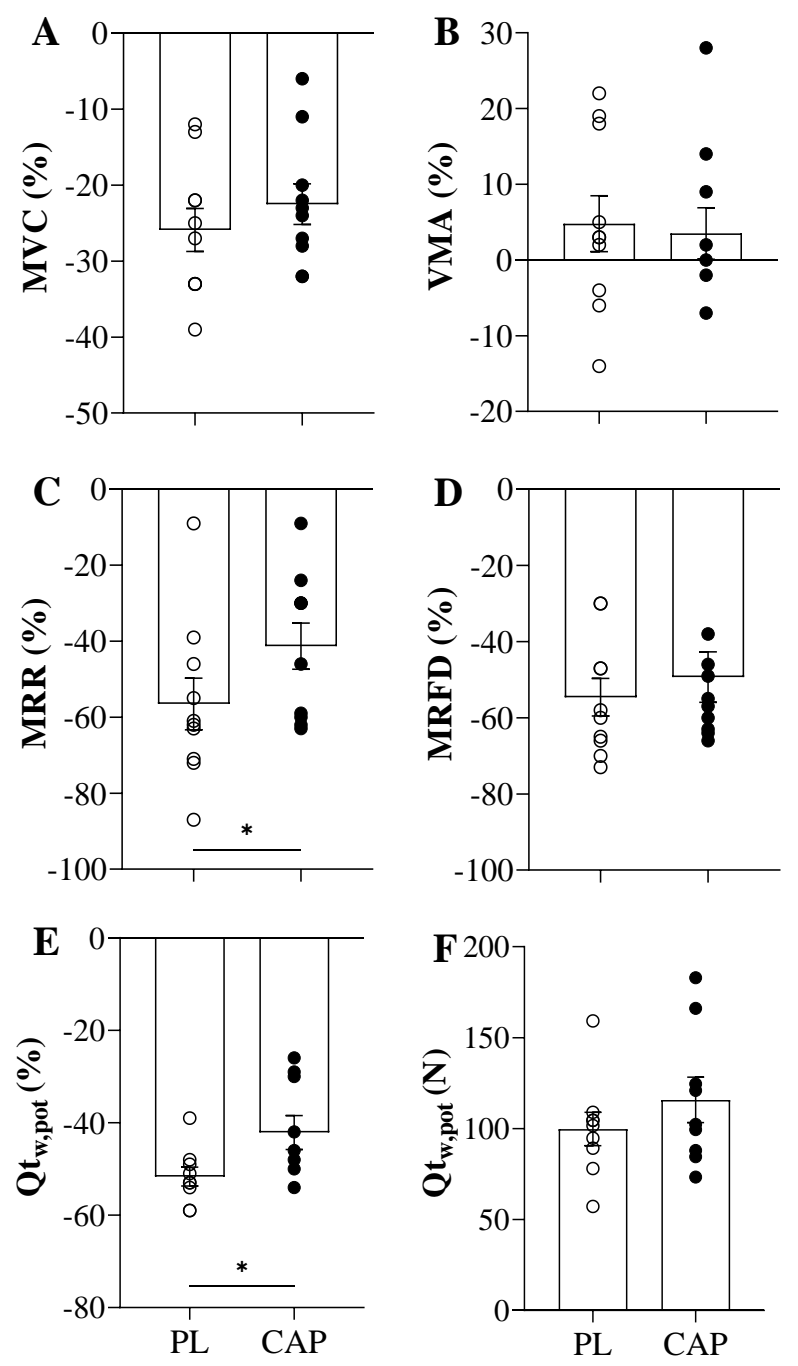

Figure 4. Neuromuscular Function Parameters expressed as the exercise-induced relative change after the time to exhaustion (TTE) in young active males $(n=10)$. (A) Maximal voluntary contraction. (B) Voluntary muscle activation. (C) Maximal relaxation rate. (D) Maximal rate of force development. (E) Resting potentiated twitch in percentual values. (F) Resting potentiated twitch in absolute values after fatigue. Values are presented as Mean \pm SEM; ${ }^{*}: p<0.05$. 


\subsection{Microvascular Oxygenation during the TTE}

Following CAP or PL ingestion, the pre-exercise levels of muscle oxygenation (StO2\%; $64 \pm 3$ vs. $68 \pm 8 \%$ ), Total Hemoglobin Content (THC; $63 \pm 23$ vs. $66 \pm 20 \mu \mathrm{M}$ ), Oxygenated Hemoglobin $(\mathrm{HbO} ; 40 \pm 14$ vs. $44 \pm 11 \mu \mathrm{M})$, and Deoxygenated Hemoglobin $(\mathrm{Hb} ; 23 \pm 10$ vs. $22 \pm 10 \mu \mathrm{M})$ were not different between conditions $(p>0.05)$. The start of the TTE modified the microvascular muscle oxygenation indexes, but the changes were not different with CAP treatment. However, the muscular circulation showed a general trend for higher values with CAP, which reversed during exercise, with THC $(77.5 \pm 28.1$ vs. $80.2 \pm 30.9 \mu \mathrm{M})$ and $\mathrm{Hb}(36.2 \pm 20.3$ vs. $40.2 \pm 19.4 \mu \mathrm{M})$ higher in the PL condition. When we look at the hyperemia during recovery, CAP showed higher levels of $\mathrm{StO} 2 \%$ as compared to PL (71.6 \pm 1.6 vs. $69.5 \pm 2.8 \%, p=0.02$ ), but there were no between-conditions differences for [THC] $(90.1 \pm 29.7$ vs. $88.9 \pm 31.8 \mu \mathrm{M}),[\mathrm{HbO}](64.7 \pm 22.0$ vs. $62.3 \pm 23.1 \mu \mathrm{M})$, and [Hb] $(25.4 \pm 7.9$ vs. $26.7 \pm 9.3 \mu \mathrm{M})$.

\subsection{Central Hemodynamics, Ventilation and Perceived Exertion during the TTE}

The indexes of the central hemodynamic (HR, SV, and CO) were not affected differently by the two conditions (Figure 5). No statistically significant condition $\mathrm{x}$ time interactions $(p>0.05)$ were observed for HR, SV, and CO during both baseline and exercise. As expected, there was a main effect of time for all the central hemodynamic markers $(p<0.00)$, but not an effect of CAP or PL administration. With CAP, the HR peak during exercise was $180 \pm 7 \mathrm{bpm}, \mathrm{SV}$ was $212 \pm 48 \mathrm{~mL} / \mathrm{min}$, and $\mathrm{CO}$ was $36 \pm 8 \mathrm{~L} / \mathrm{min}$. In accordance, with $\mathrm{PL}$ the peak of HR was $181 \pm 9 \mathrm{bpm}$, SV was $225 \pm 49 \mathrm{~mL} / \mathrm{min}$, and CO was $38 \pm 9 \mathrm{~L} / \mathrm{min}$. A significant time effect was found for the ventilatory responses to the exercise $(p<0.05)$ in $\mathrm{VO}_{2}, \mathrm{VE}$, and RER (data not shown), whereas no interaction or condition effect was shown. Furthermore, the rating of perceived exertion (Figure 5D) of both whole-body and leg increased accordingly to the advance of the exercise and irrespective of the treatment (RPEtot: $7.8 \pm 2.2$ vs. $6.9 \pm 2.8$; RPEleg: $9.3 \pm 1.3$ vs. $9.0 \pm 1.1$; all $p>0.05$ ).
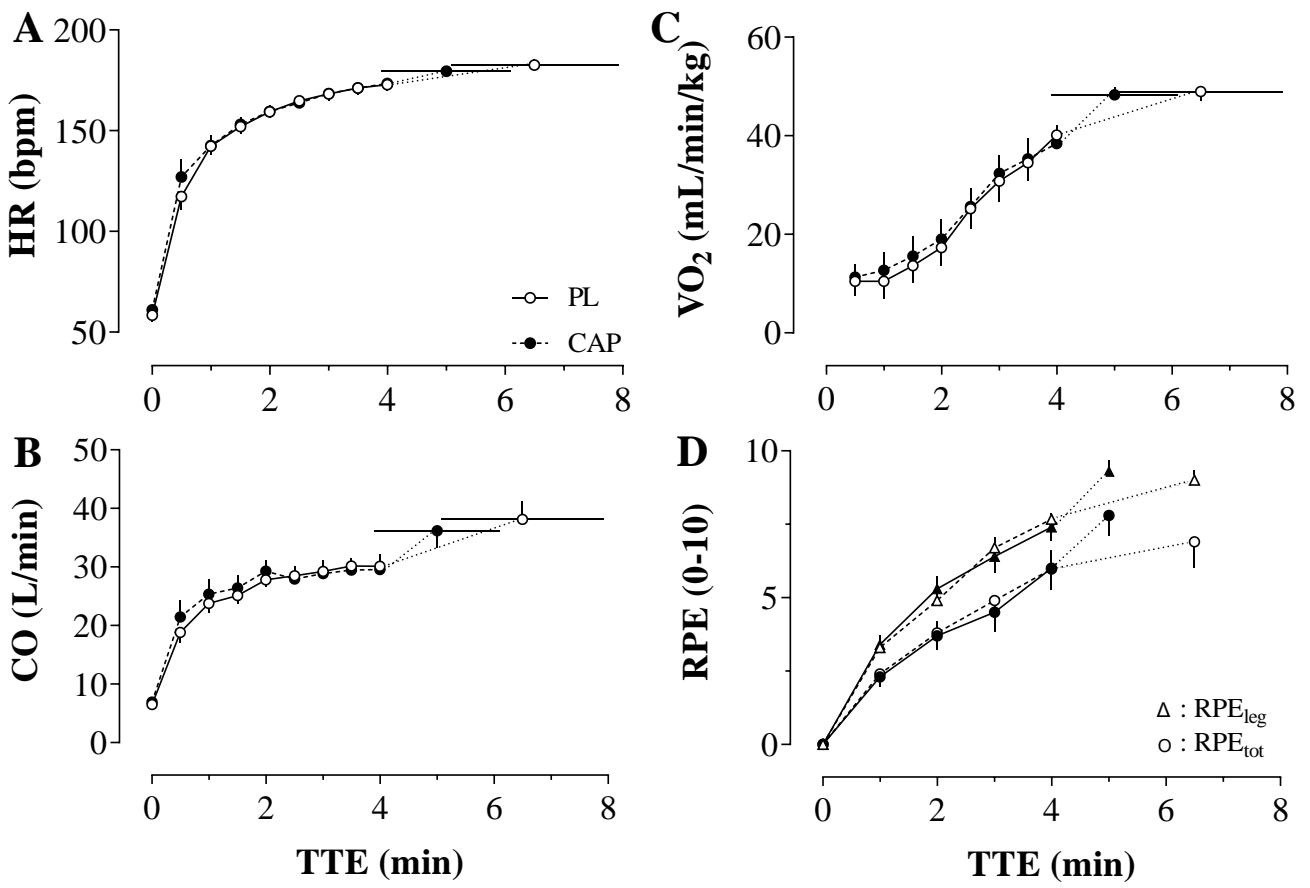

Figure 5. Central hemodynamic (Heart rate (HR); Cardiac output (CO); Panel (A,B)). Oxygen consumption $\left(\mathrm{VO}_{2}\right.$; Panel $\left.(\mathrm{C})\right)$ and perceived exertion (RPE; Panel (D)) throughout the time to exhaustion (TTE) under Placebo (PL) and Capsaicin (CAP) Conditions $(n=10)$. In panel (D), RPE is represented as the rating of perceived exertion of the lower limbs (RPEleg; triangle) and whole-body (RPEtot; dot). Values are presented as Mean \pm SEM. 


\subsection{Stress and Proinflammatory Biomarkers}

CAP did not influence salivary cortisol secretion at baseline, during, and after exercise. Indeed, there was a main effect of time $(p=0.002)$ with an increase in salivary cortisol concentration during recovery; however, CAP did not influence the overall kinetics ( $p>0.05$, Table 2). The activity of the salivary $\alpha$-amylase tended to be reduced with CAP ( $p=0.07)$, and in both conditions demonstrated a main effect of time $(p<0.001$, Table 2$)$. Looking at the interleukins, CAP increased the average salivary IL- 6 concentration $(p=0.009)$ at baseline and during the exercise, then the level decreased to PL concentrations post-exercise. Moreover, CAP tended to attenuate the post-exercise rise in IL-1 $\beta(p=0.053$, Table 2).

Table 2. Endocrine and Inflammatory Biomarkers.

\begin{tabular}{lcccccccc}
\hline & \multicolumn{2}{c}{ Baseline } & \multicolumn{2}{c}{ Exercise } & \multicolumn{2}{c}{ 10 min Post } & \multicolumn{2}{c}{ 15 min Post } \\
\cline { 2 - 8 } & PL & CAP & PL & CAP & PL & CAP & PL & CAP \\
\hline Cortisol $(\mu \mathrm{g} / \mathbf{d L})$ & $0.3 \pm 0.2$ & $0.3 \pm 0.2$ & $0.2 \pm 0.0$ & $0.3 \pm 0.1$ & $0.3 \pm 0.2$ & $0.3 \pm 0.2$ & $0.4 \pm 0.2$ & $0.4 \pm 0.2$ \\
$\alpha$-amylase (U/mL) & $31 \pm 36$ & $15 \pm 10$ & $74 \pm 41$ & $57 \pm 67$ & $42 \pm 29$ & $40 \pm 28$ & $38 \pm 27$ & $22 \pm 8$ \\
IL-6 $(\mathbf{p g} / \mathbf{m L})$ & $10 \pm 7$ & $17 \pm 14^{*}$ & $7 \pm 5$ & $13 \pm 7 *$ & $8 \pm 9$ & $10 \pm 7$ & $8 \pm 4$ & $9 \pm 5$ \\
IL-1 $\boldsymbol{\beta}(\mathbf{p g} / \mathbf{m L})$ & $20 \pm 18$ & $21 \pm 29$ & - & - & $35 \pm 40$ & $15 \pm 11$ & $32 \pm 28$ & $15 \pm 10 *$ \\
\hline
\end{tabular}

Data are presented as mean \pm SD. IL-6: interleukin 6; IL-1 $\beta$ : interleukin $1 \beta .{ }^{*}: p<0.05$ between PL and $\mathrm{CAP}$-indicates low sample volume available for assay.

\section{Discussion}

This study sought to determine the potential impact of acute oral capsaicin (CAP) administration on cycling endurance performance to exhaustion and parse out the associated physiological mechanisms underlying neuromuscular fatigue. Despite no differences between CAP and PL in cycling performance time to exhaustion, CAP did attenuate the post-exercise decline in the potentiated twitch. It partially impacted the contractile kinetics of the muscle, providing a greater rate of relaxation but no difference in the rate of contraction. CAP had no effects on the cardiorespiratory, perceptions of fatigue, or microvascular responses to the TTE trial. This suggests a potential enhancement of the sarcoendoplasmic reticulum $\mathrm{Ca}^{2+}$ ATPase (SERCA) pump activity, thereby preserving muscle relaxation. Moreover, CAP modulated changes in the pro-inflammatory interleukins, attenuating the rise of IL-1 $\beta$ during recovery. Partially in accordance with our hypothesis, CAP did not improve the time to exhaustion but it seemed to attenuate peripheral neuromuscular fatigue, increase muscle relaxation rate, and transiently alter the inflammatory response, independent of changes in cardiorespiratory or microvascular responses.

\subsection{CAP and Exercise Performance}

To date, just a few researchers have investigated the role of capsaicin during exercise in humans [28-32]. To our knowledge, this is the first study to investigate how CAP influences neuromuscular fatigue in humans in physiological terms and not just with perceptual indices. Indeed, acute CAP ingestion seems to increase performance or fatigue-resistance during a running time trial [30], high-intensity intermittent exercise [29], and resistance training [28]. However, in the present study, we did not observe any performance improvement (Figure 3), which agrees with the findings of Opheim and colleagues [32]. Previous work in rodents suggests that CAP increases performance in a dose-dependent manner [21-24], thus it is possible that the dose used in the present study was not enough to elicit a performance improvement; however, we might be the first to actually verify the capsaicin/dihydrocapsaicin content of the supplement and, importantly, we avoided any potential significant gastrointestinal distress that might have detracted from exercise performance. 


\subsection{CAP and Exercise-Induced Neuromuscular Fatigue}

In the current study, after the cycling exercise trial, the indices of locomotor muscle fatigue were all negatively affected, as expected. Indeed, both the force and the voluntary muscle activation decreased to a similar extent regardless of CAP supplementation (Figure 4). Interestingly, the exercise-induced reductions in indices of peripheral fatigue were seemingly attenuated with CAP, chiefly amongst them, the maximal relaxation rate and the magnitude of the potentiated twitch. Mechanistically, a reason for these differences may be attributable to altered $\mathrm{Ca}^{2+}$ handling. It has been already documented that during intense exercise, the $\mathrm{Ca}^{2+}$ release from the sarcoplasmic reticulum (SR) is reduced in response to a marked depletion of cellular ATP $[49,50]$, which may act to decrease the power output of the exercise and prevent peripheral fatigue from crossing a critical threshold [51]. This study investigated capsaicin, which increases the TRPV 1 channel activity which can influence the Sarco/Endoplasmic Reticulum Calcium ATPase (SERCA) pump [52] in the muscle. Elevated SERCA pump activity with CAP-induced activation of TRPV ${ }_{1}$ in muscle consequently improved the kinetics of SR $\mathrm{Ca}^{2+}$ reuptake [49,50,53], perhaps explaining the better preserved maximal rate of relaxation post-exercise. Moreover, capsaicin may promote mitochondrial depolarization and reactive oxygen species (ROS) production, at least at high doses [52], but on the other hand is also purported to have remarkable antioxidant activity [54], particularly in lower dosages. Reactive oxygen species increase substantially during intense muscle activity [51] and are known to contribute to fatigue, but the relation between redox balance and performance is complex [55]. It is tenable that CAP could, in an antioxidant capacity, counteract the fatiguing effects of elevated ROS, perhaps better maintaining neuromuscular function post-exercise, but warrants further investigation.

These outcomes highlight a potential role of CAP in attenuating the development of peripheral fatigue, perhaps via modulation of $\mathrm{Ca}^{2+}$ handling and its antioxidant effect. These findings are also supported by studies examining other antioxidants like ascorbate during exercise in healthy people $[55,56]$ and in disease $[57,58]$. Moreover, if we integrate the microcirculation results, even if we see a tendency for higher $\mathrm{StO}_{2} \%$ and $\mathrm{HbO}$ during strenuous exercise, the significant rise in $\mathrm{O}_{2}$ delivery during recovery in CAP could improve peripheral vascular function [59]. The reason for no significant differences during exercise could be that CAP may affect muscle vasculature in higher doses than the ones we administered. However, in the present study, we aimed to minimize the potential side effects of capsaicin ingestion, namely gastrointestinal distress. We did not detect any differences in the indices of central fatigue, though previous studies in rats found that CAP activates subgroups of the metabosensitive group IV muscle receptors [60], whose stimulation reflexively increases the central drive [61]. Perceptually, it was previously found that acute CAP supplementation could decrease the rating of perceived exertion during endurance [28], though this was not the case in our study, as RPE increased equally during the time to exhaustion in both CAP and PL conditions.

\subsection{CAP and the Physiological Response to Exercise}

As capsaicin has been suggested to improve exercise performance and fatigue resistance, it is important to understand how it may alter the physiological response to exercise and ultimately support greater work. To this end, previous work in animal models suggests that CAP-induced improvements in performance were associated with increased hepatic glycogen content [21], perhaps due to glycogen sparing [24], and elevated fatty acid utilization as a result of catecholamine secretion and/or activity [22]. Moreover, a single high dose of CAP was found to downregulate the expression of the mitochondria uncoupling protein $\mathrm{UCP} 3$, which reduced the energy cost for a given electrically-induced contraction [25,27]. However, in humans, no change in muscle fat oxidation has been found with acute CAP supplementation during exercise recovery [62]. In the present study, the metabolic responses were similar throughout the exercise, suggesting that acute supplementation in humans does not affect energy expenditure, measured via $\mathrm{VO}_{2}$ (Figure 5), or energy substrate selection during exercise, as assessed by the RER, at least at this relatively 
high exercise intensity paradigm. Accordingly, the central hemodynamic and ventilatory responses were also similar between trials, in line with a similar metabolic cost. In addition, the microcirculation of the limb muscle also did not differ significantly during exercise, suggesting that CAP, at least in this dose, exerts minimal vasodilatory effect on the muscles. Indeed, during the initial rest, the muscular circulation showed a general trend for higher indices of microvascular perfusion with CAP, which reversed during exercise with THC and $\mathrm{Hb}$ higher with PL. Collectively, oxygen delivery and utilization seem unaffected by CAP supplementation and do not appear to be likely candidates for improved neuromuscular fatigue.

\subsection{CAP and Neuroinflammatory Indices}

In normal conditions, cortisol concentration after acute exercise is intensity-dependent [63] and increases to peak concentrations 20-30 min after the end of the physical activity [64]. Our results confirm the increasing cortisol trend after the end of the TTE, but CAP did not exert any effect on it. Indeed, it has been seen that repeated CAP administration in rats increases and prolongs the stress response [65], maybe to levels comparable to the ones of strenuous exercise, though this is typically seen with large doses. Looking at other salivary stressor biomarkers, CAP tended to lower the salivary $\alpha$-amylase enzyme activity, perhaps indicative of lower sympathetic activity [66], perhaps via altered TRPV 1 afferent activity. Although in vitro studies have demonstrated similar results, finding that capsaicinderived compounds are potential $\alpha$-amylase inhibitors [67], thus reinforcing our findings. Another important aspect is the anti-inflammatory properties of CAP. In our results, CAP attenuates the post-exercise rise in IL-1 $\beta$, maybe blunting the proinflammatory cytokine production [39]. On the other hand, we found an increased salivary concentration of IL-6 after exercise that was unaffected by CAP [68,69], which could plausibly be the result of the strenuous performance [32,70], or the capsaicin-induced TRPV 1 activation in adipose [71], or elsewhere. IL-6 may, in this case, have metabolic consequences [11,72] rather than inflammatory given the divergence between IL-6 and IL-1 $\beta$. However, further work is needed in humans to decipher the potential impact of oral capsaicin on inflammation in humans and the potential ramifications on physiology and/or fatigue. Moreover, future research should look into larger and/or more chronic dosages of capsaicin and how they interact with lactate levels during exercise.

\subsection{Limitations of the Study}

This study was not conducted without limitation. First only young active males recruited from a college community were included, thus future work in older and/or female populations is needed. Second, the use of electrical stimulation on the muscle belly and not the femoral nerve may lead to lower neuromuscular responses. Lastly, more invasive measures of metabolism, including lactate and muscle level $\mathrm{VO}_{2}$, could be interesting to investigate during and after the exercise with CAP in future studies.

\section{Conclusions}

To our knowledge, this is the first study to investigate the effect of capsaicin on exercise performance, neuromuscular fatigue, and salivary indicators of stress and proinflammatory biomarkers in humans. Contrarily to the previous findings in humans, acute capsaicin administration did not improve exercise performance nor the rating of perceived exertion. However, it showed the capacity to attenuate peripheral fatigue development, which does not appear to result from changes in central hemodynamics, muscle oxygen delivery, or the magnitude of the central motor drive after the cycling exercise. Moreover, CAP modulated the saliva biomarkers, suggesting a potential depressed sympathetic activity and anti-inflammatory effect during the peak concentration with a late decrease in the proinflammatory markers. Collectively, capsaicin has the potential to alter the peripheral components of neuromuscular fatigue, leading to possible enhancements of exercise 
performance; the mechanisms underpinning such an observation have only begun to be understood in humans.

Author Contributions: Conceptualization, S.J.I., G.G. and M.V.; Methodology, M.V., S.J.I. and K.A.F.; Investigation, G.G., A.M., E.M.K.V.K.S., K.A.F., S.J.I. and J.G.; Analysis, G.G., A.M., E.M.K.V.K.S., K.A.F. and J.G.; Writing-Original Draft Preparation, G.G. and S.J.I.; Writing-Review \& Editing, G.G., S.J.I., M.V., E.M.K.V.K.S., K.A.F. and A.M.; Supervision, S.J.I. and M.V. All authors have read and agreed to the published version of the manuscript.

Funding: This research received no external funding.

Institutional Review Board Statement: The study protocol was conducted in accordance with the most recent revisions of the Declaration of Helsinki and was approved by the Institutional Review Board (IRB\#1807-733) and Institutional Biosafety Committees of Skidmore College.

Informed Consent Statement: Informed consent for testing and publication was obtained from all subjects involved in the study.

Data Availability Statement: The data presented in this study are available on request from the corresponding author. The data are not publicly available due to privacy and intellectual property concerns.

Acknowledgments: The authors greatly appreciate the time and effort of the people that participated to this study and Robert Restaino for his assistance. The authors would like to thank Skidmore College and the University of Verona for modest support of this collaboration and the project.

Conflicts of Interest: The authors declare no conflict of interest, financial or otherwise. The results of this study are presented clearly, honestly and without fabrication, falsification, or inappropriate data manipulation. EMKVKS was a Skidmore College visiting researcher supported by Coordenação de Aperfeicoamento de Pessoal de Nível Superior-CAPES-Brazil (scholarship: 88881.188574/2018-01). EMKVKS is supported by a CAPES doctoral study scholarship-Finance Code 001. The funders had no role in the design of the study; in the collection, analyses, or interpretation of data, in the writing of the manuscript, or in the decision to publish the results.

\section{References}

1. Vyklický, L.; Nováková-Tousová, K.; Benedikt, J.; Samad, A.; Touska, F.; Vlachová, V. Calcium-dependent desensitization of vanilloid receptor TRPV1: A mechanism possibly involved in analgesia induced by topical application of capsaicin. Physiol. Res. 2008, 57 (Suppl. 3), S59-S68. [CrossRef] [PubMed]

2. Starowicz, K.; Cristino, L.; Di Marzo, V. TRPV1 receptors in the central nervous system: Potential for previously unforeseen therapeutic applications. Curr. Pharm. Des. 2008, 14, 42-54. [CrossRef]

3. Kopanitsa, M.V.; Panchenko, V.A.; Magura, E.I.; Lishko, P.V.; Krishtal, O.A. Capsaicin blocks Ca ${ }^{2+}$ channels in isolated rat trigeminal and hippocampal neurones. Neuroreport 1995, 6, 2338-2340. [CrossRef]

4. Sim, J.H.; Kim, Y.C.; Kim, S.J.; Lee, S.J.; Suh, S.H.; Jun, J.Y.; So, I.; Kim, K.W. Capsaicin inhibits the voltage-operated calcium channels intracellularly in the antral circular myocytes of guinea-pig stomach. Life Sci. 2001, 68, 2347-2360. [CrossRef]

5. Southall, M.D.; Li, T.; Gharibova, L.S.; Pei, Y.; Nicol, G.D.; Travers, J.B. Activation of epidermal vanilloid receptor-1 induces release of proinflammatory mediators in human keratinocytes. J. Pharmacol. Exp. Ther. 2003, 304, 217-222. [CrossRef] [PubMed]

6. Basu, S.; Srivastava, P. Immunological role of neuronal receptor vanilloid receptor 1 expressed on dendritic cells. Proc. Natl. Acad. Sci. USA 2005, 102, 5120-5125. [CrossRef]

7. Almeida, V.; Peres, F.F.; Levin, R.; Suiama, M.A.; Calzavara, M.B.; Zuardi, A.W.; Hallak, J.E.; Crippa, J.A.; Abílio, V.C. Effects of cannabinoid and vanilloid drugs on positive and negative-like symptoms on an animal model of schizophrenia: The SHR strain. Schizophr. Res. 2014, 153, 150-159. [CrossRef]

8. Afari, N.; Buchwald, D. Chronic fatigue syndrome: A review. Am. J. Psychiatry 2003, 160, 221-236. [CrossRef]

9. Hsu, C.L.; Yen, G.C. Effects of capsaicin on induction of apoptosis and inhibition of adipogenesis in 3T3-L1 cells. J. Agric. Food Chem. 2007, 55, 1730-1736. [CrossRef]

10. Sarvaiya, K.; Goswami, S. Investigation of the effects of vanilloids in chronic fatigue syndrome. Brain Res. Bull. 2016, 127, 187-194. [CrossRef] [PubMed]

11. Kawabata, F.; Inoue, N.; Yazawa, S.; Kawada, T.; Inoue, K.; Fushiki, T. Effects of CH-19 sweet, a non-pungent cultivar of red pepper, in decreasing the body weight and suppressing body fat accumulation by sympathetic nerve activation in humans. Biosci. Biotechnol. Biochem. 2006, 70, 2824-2835. [CrossRef]

12. Ohnuki, K.; Moritani, T.; Ishihara, K.; Fushiki, T. Capsaicin increases modulation of sympathetic nerve activity in rats: Measurement using power spectral analysis of heart rate fluctuations. Biosci. Biotechnol. Biochem. 2001, 65, 638-643. [CrossRef] 
13. Ralevic, V.; Kendall, D.A.; Randall, M.D.; Zygmunt, P.M.; Movahed, P.; Hogestatt, E.D. Vanilloid receptors on capsaicin-sensitive sensory nerves mediate relaxation to methanandamide in the rat isolated mesenteric arterial bed and small mesenteric arteries. Br. J. Pharm. 2000, 130, 1483-1488. [CrossRef]

14. Vanner, S. Mechanism of action of capsaicin on submucosal arterioles in the guinea pig ileum. Am. J. Physiol. 1993, 265, G51-G55. [CrossRef]

15. Wang, L.H.; Luo, M.; Wang, Y.; Galligan, J.J.; Wang, D.H. Impaired vasodilation in response to perivascular nerve stimulation in mesenteric arteries of TRPV1-null mutant mice. J. Hypertens. 2006, 24, 2399-2408. [CrossRef]

16. Bratz, I.N.; Dick, G.M.; Tune, J.D.; Edwards, J.M.; Neeb, Z.P.; Dincer, U.D.; Sturek, M. Impaired capsaicin-induced relaxation of coronary arteries in a porcine model of the metabolic syndrome. Am. J. Physiol. Heart Circ. Physiol. 2008, 294, H2489-H2496. [CrossRef] [PubMed]

17. Hogaboam, C.M.; Wallace, J.L. Inhibition of platelet aggregation by capsaicin. An effect unrelated to actions on sensory afferent neurons. Eur. J. Pharm. 1991, 202, 129-131. [CrossRef]

18. Kumar, P.; Chand, S.; Chandra, P.; Maurya, P.K. Influence of Dietary Capsaicin on Redox Status in Red Blood Cells during Human Aging. Adv. Pharm. Bull. 2015, 5, 583-586. [CrossRef] [PubMed]

19. McCarty, M.F.; DiNicolantonio, J.J.; O'Keefe, J.H. Capsaicin may have important potential for promoting vascular and metabolic health. Open Heart 2015, 2, e000262. [CrossRef] [PubMed]

20. Yang, D.; Luo, Z.; Ma, S.; Wong, W.T.; Ma, L.; Zhong, J.; He, H.; Zhao, Z.; Cao, T.; Yan, Z.; et al. Activation of TRPV1 by dietary capsaicin improves endothelium-dependent vasorelaxation and prevents hypertension. Cell Metab. 2010, 12, 130-141. [CrossRef]

21. Hsu, Y.J.; Huang, W.C.; Chiu, C.C.; Liu, Y.L.; Chiu, W.C.; Chiu, C.H.; Chiu, Y.S.; Huang, C.C. Capsaicin Supplementation Reduces Physical Fatigue and Improves Exercise Performance in Mice. Nutrients 2016, 8, 648. [CrossRef] [PubMed]

22. Kim, K.M.; Kawada, T.; Ishihara, K.; Inoue, K.; Fushiki, T. Increase in swimming endurance capacity of mice by capsaicin-induced adrenal catecholamine secretion. Biosci. Biotechnol. Biochem. 1997, 61, 1718-1723. [CrossRef]

23. Oh, T.W.; Oh, T.W.; Ohta, F. Dose-dependent effect of capsaicin on endurance capacity in rats. Br. J. Nutr. 2003, 90, 515-520. [CrossRef] [PubMed]

24. Oh, T.W.; Ohta, F. Capsaicin increases endurance capacity and spares tissue glycogen through lipolytic function in swimming rats. J. Nutr. Sci. Vitaminol. 2003, 49, 107-111. [CrossRef]

25. Kazuya, Y.; Tonson, A.; Pecchi, E.; Dalmasso, C.; Vilmen, C.; Fur, Y.L.; Bernard, M.; Bendahan, D.; Giannesini, B. A single intake of capsiate improves mechanical performance and bioenergetics efficiency in contracting mouse skeletal muscle. Am. J. Physiol. Endocrinol. Metab. 2014, 306, E1110-E1119. [CrossRef] [PubMed]

26. Luo, Z.; Ma, L.; Zhao, Z.; He, H.; Yang, D.; Feng, X.; Ma, S.; Chen, X.; Zhu, T.; Cao, T.; et al. TRPV1 activation improves exercise endurance and energy metabolism through PGC-1 $\alpha$ upregulation in mice. Cell Res. 2012, 22, 551-564. [CrossRef] [PubMed]

27. Faraut, B.; Giannesini, B.; Matarazzo, V.; Marqueste, T.; Dalmasso, C.; Rougon, G.; Cozzone, P.J.; Bendahan, D. Downregulation of uncoupling protein-3 in vivo is linked to changes in muscle mitochondrial energy metabolism as a result of capsiate administration. Am. J. Physiol. Endocrinol. Metab. 2007, 292, E1474-E1482. [CrossRef] [PubMed]

28. de Freitas, M.C.; Billaut, F.; Panissa, V.L.G.; Rossi, F.E.; Figueiredo, C.; Caperuto, E.C.; Lira, F.S. Capsaicin supplementation increases time to exhaustion in high-intensity intermittent exercise without modifying metabolic responses in physically active men. Eur. J. Appl. Physiol. 2019, 119, 971-979. [CrossRef]

29. de Freitas, M.C.; Cholewa, J.M.; Freire, R.V.; Carmo, B.A.; Bottan, J.; Bratfich, M.; Della Bandeira, M.P.; Gonçalves, D.C.; Caperuto, E.C.; Lira, F.S.; et al. Acute Capsaicin Supplementation Improves Resistance Training Performance in Trained Men. J. Strength Cond. Res. 2018, 32, 2227-2232. [CrossRef]

30. de Freitas, M.C.; Cholewa, J.M.; Gobbo, L.A.; de Oliveira, J.V.N.S.; Lira, F.S.; Rossi, F.E. Acute Capsaicin Supplementation Improves 1500-m Running Time-Trial Performance and Rate of Perceived Exertion in Physically Active Adults. J. Strength Cond. Res. 2018, 32, 572-577. [CrossRef]

31. von Ah Morano, A.E.; Padilha, C.S.; Soares, V.A.M.; Andrade Machado, F.; Hofmann, P.; Rossi, F.E.; Lira, F.S. Capsaicin Analogue Supplementation Does Not Improve $10 \mathrm{~km}$ Running Time-Trial Performance in Male Amateur Athletes: A Randomized, Crossover, Double-Blind and Placebo-Controlled Study. Nutrients 2020, 13, 34. [CrossRef] [PubMed]

32. Opheim, M.N.; Rankin, J.W. Effect of capsaicin supplementation on repeated sprinting performance. J. Strength Cond. Res. 2012, 26, 319-326. [CrossRef]

33. Steensberg, A.; van Hall, G.; Osada, T.; Sacchetti, M.; Saltin, B.; Klarlund Pedersen, B. Production of interleukin-6 in contracting human skeletal muscles can account for the exercise-induced increase in plasma interleukin-6. J. Physiol. 2000, 529 Pt 1, $237-242$. [CrossRef] [PubMed]

34. Cannon, J.G.; Fielding, R.A.; Fiatarone, M.A.; Orencole, S.F.; Dinarello, C.A.; Evans, W.J. Increased interleukin 1 beta in human skeletal muscle after exercise. Am. J. Physiol. 1989, 257, R451-R455. [CrossRef] [PubMed]

35. Roerink, M.E.; van der Schaaf, M.E.; Dinarello, C.A.; Knoop, H.; van der Meer, J.W. Interleukin-1 as a mediator of fatigue in disease: A narrative review. J. Neuroinflamm. 2017, 14, 16. [CrossRef]

36. Granger, D.A.; Kivlighan, K.T.; el-Sheikh, M.; Gordis, E.B.; Stroud, L.R. Salivary alpha-amylase in biobehavioral research: Recent developments and applications. Ann. N. Y. Acad. Sci. 2007, 1098, 122-144. [CrossRef] [PubMed]

37. Jacks, D.E.; Sowash, J.; Anning, J.; McGloughlin, T.; Andres, F. Effect of exercise at three exercise intensities on salivary cortisol. J. Strength Cond. Res. 2002, 16, 286-289. 
38. Kobayashi, M.; Watanabe, K.; Yokoyama, S.; Matsumoto, C.; Hirata, M.; Tominari, T.; Inada, M.; Miyaura, C. Capsaicin, a TRPV1 Ligand, Suppresses Bone Resorption by Inhibiting the Prostaglandin E Production of Osteoblasts, and Attenuates the Inflammatory Bone Loss Induced by Lipopolysaccharide. ISRN Pharmacol. 2012, 2012, 439860. [CrossRef]

39. Tang, J.; Luo, K.; Li, Y.; Chen, Q.; Tang, D.; Wang, D.; Xiao, J. Capsaicin attenuates LPS-induced inflammatory cytokine production by upregulation of LXR $\alpha$. Int. Immunopharmacol. 2015, 28, 264-269. [CrossRef] [PubMed]

40. Noreen, E.E.; Lemon, P.W. Reliability of air displacement plethysmography in a large, heterogeneous sample. Med. Sci. Sports Exerc. 2006, 38, 1505-1509. [CrossRef]

41. Reyes-Escogido, M.D.L.; Gonzalez-Mondragon, E.G.; Vazquez-Tzompantzi, E. Chemical and Pharmacological Aspects of Capsaicin. Molecules 2011, 16, 1253-1270. [CrossRef]

42. Crouter, S.E.; Antczak, A.; Hudak, J.R.; DellaValle, D.M.; Haas, J.D. Accuracy and reliability of the ParvoMedics TrueOne 2400 and MedGraphics VO2000 metabolic systems. Eur. J. Appl. Physiol. 2006, 98, 139-151. [CrossRef] [PubMed]

43. Richard, R.; Lonsdorfer-Wolf, E.; Charloux, A.; Doutreleau, S.; Buchheit, M.; Oswald-Mammosser, M.; Lampert, E.; Mettauer, B.; Geny, B.; Lonsdorfer, J. Non-invasive cardiac output evaluation during a maximal progressive exercise test, using a new impedance cardiograph device. Eur. J. Appl. Physiol. 2001, 85, 202-207. [CrossRef] [PubMed]

44. Laginestra, F.G.; Amann, M.; Kirmizi, E.; Giuriato, G.; Barbi, C.; Ruzzante, F.; Pedrinolla, A.; Martignon, C.; Tarperi, C.; Schena, F.; et al. Electrically induced quadriceps fatigue in the contralateral leg impairs ipsilateral knee extensors performance. Am. J. Physiol.-Regul. Integr. Comp. Physiol. 2021, 320, R747-R756. [CrossRef]

45. Amann, M.; Venturelli, M.; Ives, S.J.; McDaniel, J.; Layec, G.; Rossman, M.J.; Richardson, R.S. Peripheral fatigue limits endurance exercise via a sensory feedback-mediated reduction in spinal motoneuronal output. J. Appl. Physiol. (1985) 2013, 115, 355-364 [CrossRef]

46. Giuriato, G.; Gundersen, A.; Verma, S.; Pelletier, E.; Bakewell, B.; Ives, S.J. The Effects of Chest Wall Loading on Perceptions of Fatigue, Exercise Performance, Pulmonary Function, and Muscle Perfusion. Sports 2020, 8, 3. [CrossRef]

47. Ives, S.J.; Amann, M.; Venturelli, M.; Witman, M.A.; Groot, H.J.; Wray, D.W.; Morgan, D.E.; Stehlik, J.; Richardson, R.S. The Mechanoreflex and Hemodynamic Response to Passive Leg Movement in Heart Failure. Med. Sci. Sports Exerc. 2016, 48, 368-376. [CrossRef] [PubMed]

48. Barrett-O'Keefe, Z.; Ives, S.J.; Trinity, J.D.; Morgan, G.; Rossman, M.J.; Donato, A.J.; Runnels, S.; Morgan, D.E.; Gmelch, B.S.; Bledsoe, A.D.; et al. Taming the "sleeping giant": The role of endothelin-1 in the regulation of skeletal muscle blood flow and arterial blood pressure during exercise. Am. J. Physiol. Heart Circ. Physiol. 2013, 304, H162-H169. [CrossRef]

49. Hill, C.A.; Thompson, M.W.; Ruell, P.A.; Thom, J.M.; White, M.J. Sarcoplasmic reticulum function and muscle contractile character following fatiguing exercise in humans. J. Physiol. 2001, 531, 871-878. [CrossRef] [PubMed]

50. Leppik, J.A.; Aughey, R.J.; Medved, I.; Fairweather, I.; Carey, M.F.; McKenna, M.J. Prolonged exercise to fatigue in humans impairs skeletal muscle $\mathrm{Na}+-\mathrm{K}+-\mathrm{ATPase}$ activity, sarcoplasmic reticulum $\mathrm{Ca}^{2+}$ release, and $\mathrm{Ca}^{2+}$ uptake. J. Appl. Physiol. (1985) 2004, 97, 1414-1423. [CrossRef] [PubMed]

51. Allen, D.G.; Lamb, G.D.; Westerblad, H. Impaired calcium release during fatigue. J. Appl. Physiol. (1985) 2008, 104, 296-305. [CrossRef]

52. Pingle, S.C.; Matta, J.A.; Ahern, G.P. Capsaicin Receptor: TRPV1 A Promiscuous TRP Channel. In Transient Receptor Potential (TRP) Channels; Flockerzi, V., Nilius, B., Eds.; Springer: Berlin/Heidelberg, Germany, 2007; pp. 155-171.

53. Santulli, G.; Lewis, D.; des Georges, A.; Marks, A.R.; Frank, J. Ryanodine Receptor Structure and Function in Health and Disease. In Membrane Protein Complexes: Structure and Function; Harris, J.R., Boekema, E.J., Eds.; Springer: Singapore, 2018 ; pp. 329-352.

54. Rosa, A.; Deiana, M.; Casu, V.; Paccagnini, S.; Appendino, G.; Ballero, M.; Dessí, M.A. Antioxidant activity of capsinoids. J. Agric. Food Chem. 2002, 50, 7396-7401. [CrossRef]

55. Vidal, K.; Robinson, N.; Ives, S.J. Exercise performance and physiological responses: The potential role of redox imbalance. Physiol. Rep. 2017, 5, e13225. [CrossRef] [PubMed]

56. Paschalis, V.; Theodorou, A.A.; Kyparos, A.; Dipla, K.; Zafeiridis, A.; Panayiotou, G.; Vrabas, I.S.; Nikolaidis, M.G. Low vitamin C values are linked with decreased physical performance and increased oxidative stress: Reversal by vitamin $C$ supplementation. Eur. J. Nutr. 2016, 55, 45-53. [CrossRef]

57. Hureau, T.J.; Weavil, J.C.; Sidhu, S.K.; Thurston, T.S.; Reese, V.R.; Zhao, J.; Nelson, A.D.; Birgenheier, N.M.; Richardson, R.S.; Amann, M. Ascorbate attenuates cycling exercise-induced neuromuscular fatigue but fails to improve exertional dyspnea and exercise tolerance in COPD. J. Appl. Physiol. (1985) 2021, 130, 69-79. [CrossRef] [PubMed]

58. Rossman, M.J.; Garten, R.S.; Groot, H.J.; Reese, V.; Zhao, J.; Amann, M.; Richardson, R.S. Ascorbate infusion increases skeletal muscle fatigue resistance in patients with chronic obstructive pulmonary disease. Am. J. Physiol. Regul. Integr. Comp. Physiol. 2013, 305, R1163-R1170. [CrossRef]

59. Varadharaj, S.; Kelly, O.J.; Khayat, R.N.; Kumar, P.S.; Ahmed, N.; Zweier, J.L. Role of Dietary Antioxidants in the Preservation of Vascular Function and the Modulation of Health and Disease. Front. Cardiovasc. Med. 2017, 4, 64. [CrossRef] [PubMed]

60. Hoheisel, U.; Reinöhl, J.; Unger, T.; Mense, S. Acidic pH and capsaicin activate mechanosensitive group IV muscle receptors in the rat. Pain 2004, 110, 149-157. [CrossRef]

61. Sidhu, S.K.; Weavil, J.C.; Mangum, T.S.; Jessop, J.E.; Richardson, R.S.; Morgan, D.E.; Amann, M. Group III/IV locomotor muscle afferents alter motor cortical and corticospinal excitability and promote central fatigue during cycling exercise. Clin. Neurophysiol. 2017, 128, 44-55. [CrossRef] 
62. Liao, S.F.; Korivi, M.; Tsao, J.P.; Huang, C.C.; Chang, C.C.; Cheng, I.S. Effect of Capsinoids Supplementation on Fat Oxidation and Muscle Glycogen Restoration During Post-exercise Recovery in Humans. Curr. Pharm. Des. 2021, 27, 981-988. [CrossRef]

63. Budde, H.; Machado, S.; Ribeiro, P.; Wegner, M. The cortisol response to exercise in young adults. Front. Behav. Neurosci. 2015, 9, 13. [CrossRef] [PubMed]

64. Kirschbaum, C.; Hellhammer, D.H. Salivary cortisol in psychoneuroendocrine research: Recent developments and applications Psychoneuroendocrinology 1994, 19, 313-333. [CrossRef]

65. Choi, Y.J.; Kim, J.Y.; Yoo, S.B.; Lee, J.H.; Jahng, J.W. Repeated oral administration of capsaicin increases anxiety-like behaviours with prolonged stress-response in rats. J. Biosci. 2013, 38, 561-571. [CrossRef]

66. Bosch, J.A.; Ring, C.; de Geus, E.J.; Veerman, E.C.; Amerongen, A.V. Stress and secretory immunity. Int. Rev. Neurobiol. 2002, 52, 213-253. [CrossRef]

67. Magaña-Barajas, E.; Buitimea-Cantúa, G.V.; Hernández-Morales, A.; Torres-Pelayo, V.D.R.; Vázquez-Martínez, J.; BuitimeaCantúa, N.E. In vitro $\alpha$-amylase and $\alpha$-glucosidase enzyme inhibition and antioxidant activity by capsaicin and piperine from Capsicum chinense and Piper nigrum fruits. J. Environ. Sci. Health Part. B Pestic. Food Contam. Agric. Wastes 2021, 56, 282-291. [CrossRef]

68. Ives, S.J.; Blegen, M.; Coughlin, M.A.; Redmond, J.; Matthews, T.; Paolone, V. Salivary estradiol, interleukin-6 production, and the relationship to substrate metabolism during exercise in females. Eur. J. Appl. Physiol. 2011, 111, 1649-1658. [CrossRef] [PubMed]

69. Seki, N.; Shirasaki, H.; Kikuchi, M.; Himi, T. Capsaicin induces the production of IL-6 in human upper respiratory epithelial cells. Life Sci. 2007, 80, 1592-1597. [CrossRef] [PubMed]

70. de Moura, E.S.V.E.L.; Cholewa, J.M.; Jäger, R.; Zanchi, N.E.; de Freitas, M.C.; de Moura, R.C.; Barros, E.M.L.; Antunes, B.M.; Caperuto, E.C.; Ribeiro, S.L.G.; et al. Chronic capsiate supplementation increases fat-free mass and upper body strength but not the inflammatory response to resistance exercise in young untrained men: A randomized, placebo-controlled and double-blind study. J. Int. Soc. Sports Nutr. 2021, 18, 50. [CrossRef]

71. Kikuchi, H.; Oguri, G.; Yamamoto, Y.; Takano, N.K.; Tanaka, T.; Takahashi, M.; Nakamura, F.; Yamasoba, T.; Komuro, I.; Obi, S.; et al. Thermo-Sensitive Transient Receptor Potential Vanilloid (TRPV) Channels Regulate IL-6 Expression in Mouse Adipocytes. Cardiovasc. Pharmacol. 2015, 4. [CrossRef]

72. Ghanemi, A.; St-Amand, J. Interleukin-6 as a "metabolic hormone". Cytokine 2018, 112, 132-136. [CrossRef] 